\title{
POST-FENOMENOLOGIJA TELESA
}

Ključne besede: telo, post-fenomenologija, E. Husserl, M. MerleauPonty

\section{Uvod}

Do nedavnega je le redko kdo od slovenskih sociologov kazal zanimanje za fenomenologijo. Kot svetlo izjemo lahko omenim F. Adama (1988), ki je ob neki priložnosti prevedel nekaj izbranih odlomkov iz del A. Schutza in ob tem objavil tudi spremno študijo v Novi reviji. Če bi še malo bolj temeljito pobrskali po zaprašenih policah knjižnic, bi lahko tu pa tam našli še kakšen tekst, sicer pa kakšnega posebnega interesa med (slovenskimi) sociologi na prelomu iz osemdesetih $\mathrm{v}$ devetdeseta leta prejšnjega stoletja za fenomenologijo preprosto ni bilo. Tako ali tako se je razvoj fenomenološko obarvane sociologije za nekaj časa ustavil kmalu po izidu knjige P. Bergerja in T. Luckmana (1966) The Social Construction of Reality (glej Nagataki in Hirose, 2007, 223 in Turner, 2008, 12).

Zakaj bi se danes sploh še ukvarjali z nečim, kar naj bi že zdavnaj izgubilo vso privlačnost? Nostalgija je sicer lahko dragocena kulturna kvaliteta, a zato vseeno ne sodi v resna znanstvena dela. Razlogi za revitalizacijo fenomenološke misli v sociologiji se zato skrivajo drugje. Zdi se skorajda paradoksalno, a dobršen del razlogov za ponovno odkritje fenomenologije $\mathrm{v}$ drugi polovici osemdesetih let izvira iz sociologije telesa, ne pa iz kakšne sociološke discipline, katere predmet proučevanja temelji na družbeni pogojenosti notranjih psihičnih stanj posameznika, na primer kognitivne sociologije. V uvodu h knjigi Regulating Bodies Bryan S. Turner $(1992,8)$ tako govori o fenomenologiji živega telesa. Sestavljajo jo tri teoretske tradicije: življenjska filozofija, filozofska antropologija in fenomenologija. V sinta- 
gmi živo telo se skriva zahteva, da sociologi telesa poleg interesa za simbolno telo in družbeni diskurz o telesu pokažejo zanimanje tudi za dejansko, somatsko telo. Na drugi strani C. Shilling $(2005,56)$ meni, da fenomenologiji ne uspe pojasniti, kako somatska izkušnja posamezniku predstavlja sredstvo, preko katerega se lahko posameznik vključi v družbeni kontekst. Sociologi telesa, ki sledijo fenomenologiji, se zato kaj hitro znajdejo v situaciji, ko morajo svoja razmišljanja dopolniti z elementi nekaterih teorij, za katere bi le z veliko domišljije rekli, da pripadajo fenomenološki tradiciji.

In prav to se je $\mathrm{v}$ zadnjih letih tudi zgodilo. Nova paradigma, ki je nastala $\mathrm{z}$ vstopom nekaterih drugih teoretskih elementov $\mathrm{v}$ fenomenologijo, je dobila ime post-fenomenologija. D. Ihde $(2008,6-7)$ omenja štiri ključne elemente post-fenomenologije. Prvi element je princip teoretskih variacij. Že izvorno je fenomenologija težila k teoretski odprtosti kot edinemu učinkovitemu 'zdravilu' zoper redukcionizem, post-fenomenologija pa v prostih variacijah vidi tudi mehanizem, s katerim je mogoče v raziskovalnem procesu zgraditi večstrukturno razlago nekega fenomena. Drugi element govori o tem, da mora biti post-fenomenološko raziskovanje $\mathrm{v}$ izhodišču izkustveno, čeprav ne tudi subjektivistično. Empirično raziskovanje, medsebojno preverjanje in kolegialna kritika morajo biti vsakodnevna praksa post-fenomenoloških raziskovalcev. Tretji element izvorno sicer ni fenomenološki, čeprav je v določeni meri soroden ideji intencionalnosti. Postfenomenologija se zelo močno naslanja na Deweyev pragmatizem oziroma njegovo ugotovitev, da moramo raziskovanje graditi na predpostavki o tesni povezanost med organizmom in okoljem. Preneseno v področje družboslovja gre za interakcijo med posameznikovim izkustvom in svetom življenja. Nenazadnje je tu še četrti element, ki se nanaša na zavračanje ideje o obstoju breztelesnega obče prisotnega transcedentalnega ega. Post-fenomenologija $\mathrm{z}$ idejo utelešenja oziroma pomena, ki ga imata telo in materialni svet, poveže na eni strani zahteve eksistencialne in hermenevtične fenomenologije ter na drugi strani zahteve zgodnjega ameriškega pragmatizma, po raziskovanju konkretnega materialnega sveta in znanja, vezanega na določeno izkustveno situacijo. Na žalost nimamo na razpolago dovolj prostora, da bi se spustili v podrobno analizo pomena, ki ga ima post-fenomenološka paradigma za družboslovje in humanistiko. Lahko pa si privoščimo kratek izlet $\mathrm{v}$ delo dveh klasičnih fenomenoloških avtorjev, 
in sicer E. Husserla in M. Merleau-Pontyja, katerih delo v pomembni meri vpliva na post-fenomenološko sociologijo telesa. ${ }^{1}$

\section{E. Husserl, telo in primordialnost človeškega dotika}

Naj začnem svojo razpravo s kratkim sprehodom skozi tiste elemente Husserlovega dela, za katere mislim, da so še vedno aktualni za področje sociologije telesa, pri čemer ne smemo mimo njegovega dela $\mathrm{z}$ naslovom Ideen II: Phänomenologische Untersuchungen zur Konstitution (Husserl, 1989). Gre še za en Husserlov poskus v vrsti preseganj kartezijanskega dualizma, saj je njegovo razmišljanje o vlogi telesa tesno povezano prav s prepričanjem, da lahko posameznik svojo psihično realnost vzpostavlja prav in le preko delovanja svojega telesa. Ko posameznik s svojim lastnim telesom deluje v kulturnem, družbenem in fizičnem okolju, ima le-to za posledico nastanek normalne psihične strukture. Posameznik se $\mathrm{v}$ določenem prostoru giblje, opazuje dogajanje okrog sebe in sprejema različne informacije iz okolja. Razlikovanje med telesom in okoljem je na tem mestu pomembno. Onkraj posameznikovega sebstva, ki obsega predstavo o njegovem telesu kakor tudi samo telesno pojavnost posameznika, obstaja svet predmetov, o katerem Husserl govori kot o področju zunanjih objektov. Husserla je zanimalo na videz preprosto vprašanje, na kakšen način telo vstopa $\mathrm{v}$ odnos do predmetnega sveta, ki ga obkroža. Kajti, pravi Husserl, izkušnja nam govori, da telo brez dvoma vstopa $\mathrm{v}$ razmerje do različnih predmetov in $\mathrm{s}$ tem $\mathrm{v}$ razmerje do zunanjega svet, ki je kot takšno postavljeno v vlogo sekundarnega objekta. Telo je prav tako objekt, a za Husserla telo ni predmet. Za telo velja, da ima neko stopnjo samostojnosti, medtem ko je predmet lahko zgolj predmet različnih procesov, saj za predmet velja, da je pasiven.

Način, na katerega vstopa telo v razmerje do ostalega sveta, Husserl imenuje osredinjenost telesa. Pravzaprav ne gre za nič drugega kot le za to, da telo zaznava okolje in $\mathrm{v}$ njem deluje vedno znova in le iz perspektive svojega lastnega obstoja. Telo oziroma posameznik samega sebe intuitivno razume

1 Da bi imeli popolen vpogled v klasične avtorje, iz katerih črpa postfenomenološka fenomenologija telesa, bi si morali ogledati delo vsaj še dveh avtorjev: G. H. Meada in J. Deweya. 
kot center sveta, razdalje in pomen do predmetov in pojavov zunaj centra, to je njega samega, pa posameznik meri glede na njihov položaj, njihovo oddaljenost do centra oziroma do lastnega telesa in pa glede na pomen, ki ga imajo tako predmeti za telesni obstoj posameznika. Osredinjenost posameznika oziroma njegovega telesa in s tem vstopanje posameznikovega telesa $\mathrm{v}$ kontakt $\mathrm{s}$ predmetnim svetom se zgodi v procesu percepcije. Telo je za Husserla v prvi vrsti medij vsakovrstne percepcije in kot takšno ima dve pomembni vlogi. Prvič, skozi proces zaznavanja telo omogoča posamezniku konstituiranje zunanjega sveta. Brez tega za posameznika zunanji svet sploh ne bi mogel obstajati. Drugič, skozi proces zaznavanja posameznikovo telo posameznika motivira za delovanje v zunanjem svetu. Gre za spontan in avtonomen proces, ki kot tak igra tudi pomembno vlogo pri konstruiranju prostora. Ker je percepcija notranja lastnost telesa, se obe lastnosti preneseta tudi na njegovo delovanje. Telo je v primerjavi s primarnimi objekti svobodno in 'opremljeno' z določeno stopnjo lastne volje.

Načinov, na katere vstopa posameznik preko percepcije v razmerje do zunanjega sveta sekundarnih objektov, je toliko, kolikor ima človek čutil. Toda po Husserlu je primordialen način zaznavanja, na katerega vstopa posameznik preko telesa v odnos do sveta, dotik. Posameznik ima v odnosu do zunanjega sveta na voljo dve različni vrsti dotika. Prvič, posameznik se preko telesa lahko dotika nekega poljubnega predmeta. In drugič, posameznik je tudi telo in kot tak se lahko dotika poljubnega drugega telesa. Husserl pravi, da je telo $\mathrm{v}$ dotiku sposobno refleksivnega razmerja do drugega telesa. Telo je tisto, ki se dotika in telesa se dotika. Husserl trdi celo to, da če bi ljudje imeli zgolj sposobnost vizualnega čutenja, ne pa tudi sposobnosti dotikanja, posamezniki ne bi mogli vzpostaviti odnosa do drugih. Lahko rečemo, da ima Husserl glede osnovne funkcije dotika vsekakor v veliki meri prav, saj marsikateri družbeni oziroma kulturni fenomen brez njega ne bi obstajal. Vzemimo samo za primer odnos med otrokom in materjo ali pa erotičen odnos med dvema ljubimcema. Tia DeNora (2000, 75-108) v knjigi, v kateri sicer govori o glasbi v vsakdanjem svetu, zelo lepo opiše konstruiranje občutka za glasbo in ritem pri še nerojenem otroku. Zaradi tesnega stika med bodočo materjo ter še nerojenim otrokom se otrok v maternici od 23. tedna nosečnosti dalje privaja na ritem in zvoke, ki jih proizvaja nosečniško telo. Tudi kasneje, to je v zgodnjem otroštvu, je dotik zelo 
pomemben (gl. npr. Synnott, 2005). Podobno pomemben je tesen telesni stik tudi v primeru erotične ljubezni, kjer dotik dveh ali več teles pomeni še kaj več kot zgolj vznemirljiv prehod iz javnega $\mathrm{v}$ zasebni prostor (Weitman, 1998). Moderen človek pogosto rad pozablja na telesni stik z okoljem, predvsem zato, ker si je okolje, v katerem živi, praktično že v celoti podredil in preoblikoval, a za pripadnike preprostih ljudstev je bila izkušnja dotika med kožo in materialnim svetom ena od najpomembnejših oblik vzpostavljanja vedenja o svetu (Howes, 2005).

Kljub tej sposobnosti refleksivnega dotikanja in sposobnosti človekovega telesa, da je do določene mere avtonomno v svojem delovanju, pa je za posameznika telo večinoma nevidno oziroma na nezaveden način posamezniku samoumevno. Telo nam je na voljo 24 ur na dan, ne glede na to, kje smo in kaj počnemo. In pri tem, ko nekaj počnemo, se praviloma popolnoma osredotočimo na tisto, kar počnemo, in rezultate, ki bi jih s tem radi dosegli. Pri tem pa praviloma pozabimo na svoje telo. Vsekakor je takšno stanje v veliki meri izredno praktično, saj se posameznik pri tem, kar počne, vendarle ne more ukvarjati s čisto vsem, kar je pomembno za delovanje. Samoumevnost telesa in s tem njegova odsotnost vsekakor prineseta koristno poenostavitev že tako kompleksnega posameznikovega delovanja. A v takšnem stanju posameznik praviloma vztraja le toliko časa, dokler svojega lastnega telesa zaradi takšnega ali drugačnega razloga ne zazna kot svojega lastnega telesa. Praviloma je to nek moteč dejavnik, ki preusmeri njegovo pozornost s sveta na njegovo lastno telo. Tak primer je lahko neka nenadna bolečina, s katero telo posameznika opozori na nek proces oziroma stanje, ki mu ne ugaja (prim. Leder, 1990). Husserlova ugotovitev, da je telo za posameznika nevidno, dokler ga iz nekega razloga ne zazna, je pomembna, saj je ravno to tisti mehanizem, s pomočjo katerega lahko telo samo sebi postane objekt. Ko je $\mathrm{v}$ začetku devetdesetih let prejšnjega stoletja prišlo do obrata k telesu kot relevantnemu družbenemu dejavniku, se pogosto na jeziku sociologov telesa pojavi ista, čeprav nekoliko parafrazirana trditev: posameznik je telo in posameznik ima svoje telo (Crossley, 2001 in 2006; Shilling, 1993 in 2005; Turner, 1991 in 1996). ${ }^{2}$

2 Sprva Bryan S. Turner, naslanjajoč se na delo Petra L. Bergerja in Alena Gehlena, namesto o dihotomiji imeti - biti telo govori o trihotomiji delovati - imeti - biti telo (glej Turner 1992, 16). 
Videli smo, da pri Husserlu posamezniki stopajo v stik z zunanjim svetom $s$ pomočjo delovanja svojega lastnega telesa $v$ procesu zaznavanja. Seveda nas še posebej zanima simbolno navezovanje stikov med ljudmi v področju družbenega sveta. ${ }^{3} \mathrm{Z}$ drugo besedo, zanima nas proces intersubjektivnosti med posamezniki. Podobnost, pravi Husserl v delu Méditations cartésiennes, med posameznikovim telesom in telesom drugih ljudi je osnova za izkustvo drugih (Husserl, 1961). ${ }^{4}$ Husserlovo razmišljanje o položaju posameznika v svetu se vedno znova vrti okrog osamljenega, od preostalega sveta ločenega posameznika. Husserl se je te težave dobro zavedal, vendar se je nikakor ni mogel znebiti. V spoznanju, da so nam drugi ljudje podobni, a ne samo po zunanjosti, ampak tudi navznoter, to je duševno, je Husserl iskal oporno točko. Toda tudi poskus, da bi se zaprtosti posameznika rešili s percepcijo podobnosti teles, se pri Husserlu konča dokaj klavrno. Vse skupaj se zatakne ob predpostavki, da je posameznik sposoben prepoznati podobnost med lastnim in drugim telesom takrat, kadar lahko objektivizira svoje lastno telo. S tem se je sicer mogoče strinjati, vendar pa objektivizacija lastnega telesa že predpostavlja polno uveljavitev principa intersubjektvnosti, za kar v resnici Husserlu dejansko tudi gre.

Gre torej za nekakšno tavtološkost, saj svojega lastnega telesa ne morete prepoznati kot takšnega, če prej oziroma hkrati ne prepoznate tudi tujih teles kot tujih teles in obratno. Tudi sicer koncept posameznikove osredinjenosti oziroma njegovega telesa po Holensteinovem mnenju temelji na treh idealističnih predpostavkah. Kot prvo, Husserl je popolnoma zanemaril dejstvo, da v trenutku, ko se abstrakten prostor napolni z dejansko obstoječimi objekti, slednji aktivno delujejo v konstruiranju usmeritve tega

3 Husserl (1990) je avtor koncepta svet življenja, za katerega je značilen netematizirani horizont pomenov. Lahko si predstavljamo, da je človekovo telo zaradi svoje vseprisotnosti osnoven element sveta življenja. Vseeno pa v tem tekstu uporabljam izraz družbeni svet, kajti družbeni svet je še kaj več kot le svet življenja.

4 Husserlovo opažanje, da je posameznik sposoben $\mathrm{v}$ drugih posameznikih prepoznati podobnost s samim seboj, je za nas zanimiva še dandanes. Obstaja cela vrsta študij, v katerih se avtorji lotevajo sociološke analize o tem, $\mathrm{s}$ kom oziroma katerimi družbenimi skupinami se posamezniki radi primerjajo. Brez dvoma je $\mathrm{v}$ tem trenutku najbolj razvpito in problematično vprašanje, s kom se primerjajo mladostniki glede svoje telesne teže, kajti vse prepogosto gre za primerjanje $\mathrm{z}$ anoreksičnim modelom idealne zunanje podobe, ki pa jo le malokateri mladostnik lahko doseže brez resnih težav z zdravjem (gl. Franzoi in Klaiber 2007). 
prostora. Kot drugo, Husserl je v želji, da bi pojasnil vsa razmerja, v katerih stvari konstituirajo same sebe, spregledal, da njihova pojasnitev vpliva na usmeritev zaznavanja in da niso prisotni na ravni zavednega ali pa vsaj niso poudarjeni v izkustvu in kot takšni ne delujejo motivacijsko v enaki meri. Kot tretje, Husserl pri svojem razmišljanju sledi samoumevni predpostavki, ki v realnosti nikdar ni bila potrjena, in sicer da izvor konstitucije deluje tudi kot center konstituiranega. Pri tem pa pozabi na dialektičen princip, ki se pojavi med naturansem in naturatumom in ki omogoča principu orientacije njegovo polno delovanje (Holenstein, 1999, 90).

Kasneje je bil Husserl tarča mnogih kritik in njegovi učenci, pri čemer imam v mislih M. Heiddegra, A. Schutza ${ }^{5}$ in M. Merleau-Pontyja, so se $\mathrm{v}$ veliki meri odmaknili od njegove transcedentalne fenomenologije. Vendarle pa je njegov vpliv na sociologijo telesa v poznih 90. letih prejšnjega stoletja ponovno izpričan. Gre za obdobje, ko so sociologi ponovno odkrili mnogo prezgodaj umrlega francoskega filozofa M. Merleau-Pontyja. Predvsem gre na tem mestu izpostaviti tudi delo N. Crossleya, ki pa se je Husserlovih idej 'nalezel' praktično nevede in to v precejšnji meri prav skozi branje del M. Merleau-Pontyja in P. Bourdieuja. Crossley (2001, 130-133) si je pri Husserlu izposodil idejo tipifikacije in primerjave posameznikovih izkušenj. Skozi tipifikacijo posamezniki formirajo v obliki navad različne percepcijske sheme, s katerimi poenostavijo informacijsko kompleksnost percepcije. Izkušnje se pri posameznikih nalagajo v obliki vsakdanjih navad in praktičnega znanja. Vedno, kadar posamezniki naletijo na neko novo situacijo, jo primerjajo, največkrat povsem avtomatično, $\mathrm{z}$ že uveljavljeno shemo. Predvsem pa se mi zdi, da je Crossleyu pogodu način, na katerega je Husserl opravil z Descartesovo delitvijo človeka na um in telo (Crossley, 2001, 16), ter to, da je Husserl trdno stal na stališču, da je telo hkrati objekt in subjekt. Toda poglavitni razlog, zaradi katerega danes družboslovci, nekoliko manj pa humanistični misleci ne vedo več čisto dobro, kaj bi s Husserlom oziroma njegovimi idejami, je ta, da mu ni uspelo v zadovoljivi meri pojasniti, kako premostiti prepad med solipsističnim in v družbo umeščenim posameznikom (Reynaert, 2001) oziroma pojasniti procesa intersu-

5 V resnici Schutz formalno nikdar ni bil Husserlov učenec, vseeno pa ne vidim razloga, da Schutza, glede na filozofsko tradicijo, ki ji je sledil, ne bi uvrstili med Husserlove učence. 
bjektivnosti. Tu pa je ljubezni med filozofijo in družboslovjem praviloma zelo hitro konec.

\section{Merleu-Ponty, percepcija in biti-telo-v-svetu}

Ključen element Merleau Pontyjevega dela je percepcija in pa tisto, čemur z nekoliko zapletenim filozofskim jezikom, tako značilnim za fenomenologijo, rečemo biti-telo- $v$-svetu. Njegovo največkrat navajano delo je Phénoménologie de la perception iz leta 1945. Ideja percepcije ima brez dvoma pomembno mesto, kljub temu pa ne smemo pozabiti, da je Merleau-Ponty v ospredje postavljal tudi vlogo govora, gest in čustev, ki se vedno pojavijo $\mathrm{v}$ tesni povezavi s posameznikovo percepcijo. Merleau-Ponty percepcije ne razume niti $\mathrm{v}$ racionalističnem niti $\mathrm{v}$ empiricističnem smislu. Medtem ko je v prvem primeru znan subjekt, je v drugem primeru znan objekt percepcije. Ne gre mu za osamljeni subjekt niti za izolirani objekt, ampak za njuno smotrno povezanost. Percepcija je proces, v katerem je na eni strani tisto, kar vidimo, tipamo, vohamo, slišimo in okušamo, ${ }^{6}$ skratka, gre vedno za nek materialni pojav, ki ga zaznavamo s svojimi čutili; na drugi strani pa je pomen, ki ga ima lahko za posameznika takšen materialen pojav. V resnici je celo napačno govoriti o tem, da sta vsak na svojem koncu, saj sta med seboj nerazdružljivo prepletena. Zato Merleau-Ponty ni bil pripravljen sprejeti trditve, da je percepcija posameznikova notranja reprezentacija zunanjega sveta. Ko posameznik deluje v svetu, mu percepcija omogoča, da deluje kot celovita osebnost. Podobno kot G. H. Mead (glej 1934) tudi Merleau-Ponty verjame, da posameznikova osebnost lahko nastane samo kot posledica posameznikove psihofizične interakcije z okoljem. Z drugo besedo bi slednje lahko imenovali tudi telesna refleksivnost.

Poleg koncepta percepcije je za pravilno razumevanje Merleau-Pontyjeve filozofije potrebno omeniti tudi koncept delovanja. Deloma je koncept

6 Ob branju Merleau-Pontyjevih del dobimo občutek, kakor da mu je šlo v prvi vrsti za vid, $\mathrm{v}$ resnici pa to še zdaleč ni res. Zdi se, kakor da je Merleau-Ponty o vidu govoril preprosto zato, da je svojo razlago poenostavil in pri bralcu lažje dosegel razumevanje svojih del. To pa seveda še en pomeni, da je imel Merleau-Ponty vseeno prav, saj je zaradi tega bolj malo vedel povedati o delovanju drugih čutov. 
vsebovan že v njegovi trditvi, da je posameznik s pomočjo svojega telesa aktiven v svetu. In ker je posameznik aktiven v svetu s svojim telesom $s$ pomočjo percepcije, je tako percepcija postavljena $\mathrm{v}$ samo jedro posameznikovega delovanja. Samo če gledamo, vonjamo, poslušamo, se dotikamo in okušamo, lahko spoznavamo svet okoli sebe in v njem hkrati tudi delujemo. Koncept delovanja oziroma njegovo izpeljanko izkušnjo je Merleau-Ponty povezoval s svojim nasprotovanjem kartezijanskemu pogledu na povezavo oziroma ločenost med umom in telesom, kar je lepo razvidno iz sledečega odlomka iz njegove knjige: "Zlitje duše in telesa v delovanju, sublimacija biološkega $v$ posameznikov osebni obstoj, naravnega $v$ kulturni svet, je mogoče, in od tega tudi zavisi, zaradi časovne strukture našega izkustva." (Merleau-Ponty, 1962, 97).

A glede na zgoraj povedano je prisoten vsaj še en element, ki posamezniku omogoča delovanje v svetu. Gre seveda za njegovo telo. Telo je edino posameznikovo aktivno sredstvo, $s$ katerim biva $\mathrm{v}$ fizičnem in kulturnem svetu. Merleau-Ponty o osredinjenosti posameznikovega telesa razmišlja podobno kakor Husserl, kar ni nič nenavadnega, saj je bil Merleau-Ponty sprva njegov učenec. Telo, pravi Merleau-Ponty, je točka, s katere posameznik zre v svet. Telo je situirano izkustvo v fizičnem in družbenem svetu in nikakor ni pasivno. Ravno nasprotno. Telo je v svetu, ker je aktivno - in ker je aktivno na praktičen način. Telo ni samo nekaj, kar posamezniku omogoča, da zre v svet, ampak je tudi samo $v$ intencionalnem zainteresiranem odnosu do sveta. Telo ima vedno dve senzorni plati: telo vidi in je videno, telo sliši in je slišano, telo tipa in je otipano, telo okuša in je okušano, telo vonja in je vonjano. Telo je v posebnem odnosu do predmetnega sveta, na kar kaže naslednji odlomek iz Merleau-Pontyjeve knjige:

»Če stojim, držeč svojo pipo v sklenjeni dlani, pozicija moje dlani ni opredeljena s kotom, ki ga tvori $z$ mojo podlaktjo in moja podlaket $z$ mojim trupom in moj trup s tlemi. Brez dvoma vem, kje je moja pipa, in tako vem, kje sta moja dlan in moja roka, tako kot je preprost človek $v$ puččavi vedno sposoben določiti svoj položaj, ne da bi se v mislih vračal nazaj in sešteval razdalje, ki jih je premeril, odkar se je odpravil na pot." (MerleauPonty, 1962, 115) 
Merleau-Ponty bi nas rad opozoril, da ni posameznikovo telo tisto, ki samo določa svoj položaj, ampak ima vedno neko referenčno točko nekje v zunanjem svetu oziroma v svetu predmetov. Seveda telesu nikdar ni referenčna točka celoten predmetni svet. Kakor sem že dejal, je tudi za posameznikovo telo in ne samo za njegov um značilna določena stopnja intencionalnosti. Izraz intencionalnost pomeni, da je posameznikovo telo usmerjeno proti določeni točki oziroma predmetu in v skladu s to svojo usmerjenostjo posameznikovo telo tudi deluje. Do vzpostavitve referenčne točke pride zaradi procesa saturacije oziroma nasičenja intencionalnosti (Steinbock, 1999).

Ko Merleau-Ponty govori o vlogi jezika - pri čemer vztraja na tem, da je jezik le abstrakten sistem lingvističnih pravil, ki v resnici nikjer ne obstajajo, kajti kar dejansko obstaja, je le govor, jezik pa je zgolj napor človekovega uma, da bi si razložil delovanje govora -, dejansko govori o nečem podobnem, kar sem zapisal že odstavek ali dva višje. Merleau-Ponty namreč pravi, da telo govori in da je telo hkrati tudi ogovorjeno s strani drugih teles. Oziroma če stopimo še korak dalje, telo govori in o njem se druga telesa pogovarjajo. Za primer lahko vzamemo moško-žensko razmerje, v katerem dva ali več moških z očmi požirajo kakšno mimoidočo damo, pri čemer kdo od njih navrže tudi kakšno opazko, seveda tako, da po možnosti dama tega ne sliši. Kar se tiče spolov, velja včasih tudi obratno. Posledice trditve o tem, kako telo govori o drugih telesih in kako je telo hkrati tudi nagovorjeno, sploh niso nedolžne, saj kot na nekem mestu trdi Crossley (1995), med nekaterimi sociologi telesa vlada prepričanje, da teorije o telesu kot o objektu diskurza in teorije o realnem telesu ni mogoče združiti pod isto streho, ne da bi pri tem imeli resne ali celo nepremostljive težave. Merleau-Ponty je problem poskušal rešiti tako, da je diskurz razglasil za telesno zadevo. Identično je Merleau-Ponty opravil tudi z vprašanjem o družbenem delovanju moči. Posameznikovo telo je mesto, od koder izvira družbena moč, hkrati pa je tudi tarča družbene moči. Kot ilustracijo slednjega lahko bralko oziroma bralca napotim na zgodovino telesnega kaznovanja, kajti kaj pa je telesno kaznovanje drugega kot to, da eno telo fizično deluje na drugo telo, in to $\mathrm{z}$ namenom, da bi bilo prvemu telesu ravno prav 'neprijetno' in bi bilo po tej poti disciplinirano (Foucault, 1995). 
Včasih Merleau-Ponty za preplet, ki ga tvorijo percepcija, telo in njegova okolica, uporablja tudi izraz meso. S tem izrazom Merleau-Ponty meri tako na mesnatost telesa, ki vsebuje zgoraj opisano telesno dvojnost v percepciji, kakor tudi na mesnatost sveta, $s$ katerim je posameznik preko svojega telesa v stiku. Spet drugič za isto stvar uporablja izraz telesna shema. Z izrazom telesna shema Merleau-Ponty meri na splošno predzavestno zavedanje pozicije, ki jo ima posameznikovo telo v svetu. Posameznik se na ta svet ne rodi z dokončno izdelano telesno shemo. Sicer ima nekakšno telesno shemo tudi novorojenček, a je ta zelo rudimentarna in ustreza zgolj pogojem njegovega bivanja $v$ materinem telesu. Telesna shema posameznika se razvije postopoma skladno $\mathrm{z}$ njegovim celostnim razvojem oziroma $\mathrm{v}$ skladu $\mathrm{z}$ njegovim delovanjem $v$ njemu lastnem fizičnem in družbenem svetu. To pa pomeni, da je po Merleau-Pontyju telesna shema posameznika vedno tudi družbeno konstruirana, kar zopet pomeni, da je telesna shema do določene mere individualizirana in pogojena s strukturo družbene skupnosti, katere član je posameznik. Telesna shema je tesno povezana z nečim, kar lahko srečamo že pri Marcelu Maussu (1935), to je s habitualnostjo. Telesna shema je ožji pojem od habita. V razpravi o habitualnosti Merleau-Ponty pojasnjuje način, na katerega se telesna shema povečuje, in način, na katerega se telesna shema spreminja. Povrhu vsega pa je telesna shema tudi proces sprejemanja novih principov delovanja in znanje, ki posamezniku omogoča nove načine telesnega delovanja v svetu in njegovo razumevanje.

Drew Leder (1999) o Merleau-Pontyjevem konceptu mesnatosti telesa govori, no, ne ravno $\mathrm{v}$ kritičnem ampak prej v dobrohotnem dopolnilnem slogu. Njegovo razmišljanje se navezuje na Schutzovo razlikovanje med dogodkom na površini in dogodkom pod površino človekovega telesa, tako kot o tem govori A. Schutz. ${ }^{7}$ Leder trdi, da je mesnato razumevanje telesa

7 Schutz je o telesu razmišljal kot o somatski izkušnji tu-biti. Vsa človeška bitja so bitja-zasmrt. A to je le ena od manj zanimivih dimenzij razumevanja telesa pri Schutzu. Precej več obeta njegova tipologija dveh telesnih dogodkov. Prvi dogodek Schutz imenuje dogodek na površini človekovega telesa in se nanaša na zmožnost posameznika, da s preoblikovanjem površine telesa ustvari simbolno govorico telesa. Slednja je pomembna zato, ker posameznikom omogoča sporočanje notranjih stanj zavesti drugim posameznikom v procesu sporazumevanja. Schutz dogodek na površini človekovega telesa ilustrira z zardevanjem in nasmehom na obrazu posameznika. Drugi dogodek Schutz imenuje dogodek pod površino človekovega telesa in je tesno povezan s posameznikovo sposobnostjo tvorjenja védenja. Te- 
pri Merleau-Pontyju primerljivo $\mathrm{z}$ dogodkom na površini človekovega telesa, s čimer se moram do določene mere strinjati. Leder tudi smatra, da je bil Merleau-Ponty na to, kar se dogaja pod površino človekovega telesa, premalo pozoren, ali pa zaradi svoje mnogo prezgodnje smrti enostavno ni imel priložnosti, da bi svoje razmišljanje $\mathrm{v}$ tej smeri razvil do konca. Leder predlaga, da bi Merleau-Pontyjev termin mesnatost 'raztegnili' v izraz mesnatost in kri, s čimer bi zajeli tudi dogajanje pod površino posameznikovega telesa v področje delovanja telesnih organov. Če za mesnatost telesa pri Merleau-Pontyju velja, da lahko v skladu z njo izrečemo trditev 'Jaz lahko', potem za delovanje telesnih organov lahko izrečemo trditev 'Oni lahko'. Če lahko površino telesa, pravi Leder, nadziramo oziroma zanjo pravimo, da je lahko predmet zavestnih procesov, velja za področje, ki se skriva globoko v posamezniku, za slabo kontrolirano področje oziroma za področje nezavednih procesov.

Ne bom trdil, da se mi zdi termin mesnatost in kri ravno najbolj posrečen. Prej se mi zdi, da kaže na Lederjevo slabo poznavanje fenomenološke sociologije, česar pa mu ne smemo preveč zameriti. Tudi ni res, da gre Lederjevo zadevo s telesnimi organi v celoti primerjati z Schutzovim dogodkom pod površino človekovega telesa. Je pa res, da sam nikdar pri branju Merleau-Pontyjevih nisem imel občutka, da bi Merleau-Ponty imel karkoli zoper razkrivanje tistega, kar se dogaja globoko pod površjem človeškega telesa. Upal bi si celo trditi, da je Merleau-Ponty s tem, ko je uporabil izraz mesnatost telesa, že bil na dobri poti do cilja in bi tja tudi prispel, če mu tragična usoda tega ne bi preprečila.

Feministične kritike Merleau-Pontyja se osredotočijo na dva problema. Prvi val feministične kritike leti na Merleau-Pontyjevo predpostavljanje izkušnje kot nepristranskega kriterija sprejemanja oziroma vzpostavljanj znanja. Feministkam, kot je na primer Olikowska, takšna stališča rada sedejo, ker menijo, da je vsaka izkušnja posameznika že v naprej kulturno in

lesno védenje je najbolj preprosta oblika znanja, katerega osnovna značilnost je, da je zaradi svoje preprostosti neposredno dostopen zgolj posamezniku samemu, ki lahko sporoča svoje individualizirano obliko telesnega vedenja le, $\mathrm{v}$ kolikor jo ustrezno preoblikuje v neko višjo stopnjo védenja. Bolečina, na primer, je takšna oblika telesnega védenja (Schutz 1962, 1970; gl. tudi Krpič 2003). Na našo žalost pa Schutz dlje kot do fragmentarnega omenjanja obeh zgoraj opisanih dogodkov ni nikdar prišel. 
družbeno opredeljena. Drugi val feministične kritike leti na Merlo-Pontyjev koncept anonimnosti telesa (Gaudelius in Garoian, 2007; 14, gl. tudi Sullivan, 1997). Obe pripombi sta $\mathrm{v}$ resnici tesno povezani ena $\mathrm{z}$ drugo. $\mathrm{Za}$ feministke, pa ne samo za feministke, ampak tudi za vse tiste, ki imajo vsaj malo občutka za razliko med spoli, telo ne more biti brezoblično, brezspolno telo. Čeprav je tudi res, da je v neki družbi spolov lahko skoraj toliko, kolikor si jih člani te družbe 'skonstruirajo', pa to še zdaleč ne sme voditi do tega, da jih lahko že kar odmislimo. Prav nasprotno. Izkušnja svojega lastnega telesa vedno pomembno vpliva na posameznikovo percepcijo sveta.

Crossleyeva kritika Merleau-Pontyjevega dela meri predvsem na njegov pomanjkljiv občutek za politično naravo vizualnega oziroma točneje za samo politično diferenciranje vizualnega. Crossley, ki ga poleg družbenosti telesa med drugim kot sociologa zanimajo tudi družbena gibanja, ima pri tem $\mathrm{v}$ mislih različno vizualno identiteto, ki izvira iz politične orientacije posameznega gibanja in na splošno iz katerega koli javnega političnega izražanja in političnega delovanja (Crossley, 1996, 31). Nadalje Crossley očita Merleau-Pontyju, da je bil premalo konkreten glede analize medsebojnih razmerij, saj je njegov opis mikro razmerij med posamezniki, čeprav korekten, popolnoma abstrakten. Ker Merleau-Ponty preskoči z mikro na marko nivo, ali kot bi dejal Crossley, z abstraktne obravnave medsebojnih odnosov med posamezniki na obravnavo zgodovinskih družbenih sistemov, pri čemer zanemari nivo intersubjektivnosti in vpliv delovanja kulture, ki oba nivoja med seboj povezuje, mu zaradi tega ne uspe opisati raznolikosti in intenzivnosti različnih družbenih razmerij.

\section{Sklepne misli}

Tako Husserl kot Merleau-Ponty predstavljata pomemben fenomenološki vir post-fenomenološki sociologiji telesa. Obema avtorjema je blizu osredinjenost telesa v odnosu do sveta. Oba vidita v procesu percepcije ključen mehanizem, s pomočjo katerega posameznik vzpostavlja svoj odnos s svetom in obratno. Se pa avtorja razlikujeta glede vprašanja, katera oblika percepcije je za človeka bolj pomembna. Merleau-Ponty nekoliko bolj potencira vid, Husserl pa tip. Ker si lahko privoščimo časovno nekoli- 
ko oddaljen zgodovinski pogled na njuno delo, lahko rečemo, da si Husserl in Merleau-Ponty dejansko sploh ne nasprotujeta, ampak se med seboj prej dopolnjujeta. Res je sicer, da je percepcija pri Husserlu namenjena (neuspešnemu) 'reševanju' transcedentalnega subjekta, medtem ko je MerleauPontyju za transcedentalni subjekt malo mar in ga percepcija zanima kot sredstvo, preko katerega posameznik deluje v svetu. Njuna pogleda na percepcijo sta, kar se tiče prevladujoče forme, takole nekoliko poenostavljeno rečeno, komplementarna in pri obeh avtorjih vodita k razumevanju procesa intersubjektivnosti, čeprav je seveda treba takoj priznati, da sta bila avtorja pri tem različno uspešna. Tisto, zaradi česar se zdita avtorja zanimiva, pa je njun pogled na izkustvo. $\mathrm{V}$ primeru post-fenomenološke sociologije telesa gre za izkustvo živega telesa. Kot sem poudaril že uvodoma, ko sem citiral Ihdejevo delo, se fenomenologija in post-fenomenologija razlikujeta $\mathrm{v}$ tretjem, predvsem pa $\mathrm{v}$ četrtem elementu, kjer gre za zavračanje ideje breztelesnega občeprisotnega transcedentalnega subjekta. Če fenomenologija še vedno v določeni meri v tem smislu nekoliko boleha, pa post-fenomenologija na tem mestu lahko fenomenološkim vsebinam doda elemente pragmatizma. Husserl in Merleau-Ponty sta, kot smo videli v besedilu, pomembna zato, ker premik od prvega $\mathrm{k}$ drugemu fenomenološkem mislecu omogoča vdor pragmatizma v post-fenomenologijo.

In za živo in do neke mere tudi avtonomno človekovo telo danes v sociologiji telesa še najbolj gre. Zahteve po družboslovnem raziskovanju živega telesa so stare toliko kot sociologija telesa sama. Pojavijo se nekako sočasno $s$ tragično smrtjo francoskega filozofa $M$. Foucaulta v osemdesetih letih prejšnjega stoletja in sicer med drugim kot odgovor na njegovo pretirano poudarjanje zgodovinskega konstruiranja telesa oziroma, če smo natančni, telesnih reprezentacij (Butler, 1999). A bodimo pri oceni položaja, ki ga ima fenomenološka teorija telesa v področju post-fenomenološke sociologije telesa, dosledni. Turner (1996, 76-81) pravi, da trditev, da posameznik ima in hkrati tudi jê svoje lastno telo in da je zaradi tega odgovoren za svoja dejanja, čeprav lahko njegovo telo reagira povsem spontano, sicer pravilna, je pa res da je fenomenologija $v$ splošnem zaradi svoje individualistične narave neuspešna pri oblikovanju sistematične teorije o socialni strukturi, ki povzroča neenakomerno distribucijo telesne nadvlade. Posledično tudi ne obravnava, po Turnerjevem mnenju, ene od ključnih tem v sociologi- 
ji, regulacije telesa $\mathrm{v}$ interesu javnega zdravstva, ekonomije in političnega reda. Podobno razmišlja tudi Shilling, ki sicer glede nekaterih kvalitet hvali fenomenološki pristop $\mathrm{k}$ analizi telesa. Predvsem gre pri tem za uspešno osredotočenje na telesne sposobnosti, ki omogočajo telesu, da postane pomemben vir sebstva in s tem tudi konstruiranja družbe. Toda pri tem nas Shilling svari, da nikakor ne smemo pozabiti, da instrumentalna produktivnost še ni vse. V zakup je potrebno vzeti vsaj še izrazne in kreativne potenciale človekovega utelešenja (Shilling, 2005, 60, gl. tudi Shilling, 2008).

\section{LITERATURA}

Adam, F., Fenomenologija vsakdanjega življenjskega sveta kot izhod iz krize (pozitivističnega) družboslovja, Nova revija (1988), 15861597.

Berger, P., Luckmann, T., The Social Construction of Reality: A treatise in the Sociology of Knowledge, New York 1966.

Butler, J., Revisiting Bodies and Pleasures, Theory, Culture \& Society 16 (1999), 11-20.

Crossley, N., Merleau-Ponty, The Elusive Body and Carnal Sociology, Body \& Society 1 (1995), 43-63.

Crossley, N., Intersubjectivity: The Fabric of Social Becoming, London 1996.

Crossley, N., The Social Body: Habit, Identity, and Desire, London 2001.

Crossley, N., Reflexive Embodiment in Contemporary Society, New York 2006.

DeNora, T., Music in Everyday Life, Cambridge 2000. 
Franzoi, S. L., Kleiber, J. R., Body Use and Reference Group Impact: With Whom Do We Compare Our Bodies?, Sex Roles 56 (2007), 205-214.

Foucault, M., Discipline and Punish: The Birth of the Prison, New York 1995.

Gaudelius, Y., Garoian, C., Performing Embodiment: Pedagogical Intersections of Art, Technology, and the Body, v: Springgay, S., Freedman, D., Curriculum and the Cultural Body, New York 2007, 3-19.

Holenstein, E., The Zero-Point of Orientation: The Placement of the I in Perceived Space, v: Welton, D., The Body: Classic and Contemporary Readings, Malden 1999, 57-94.

Howes, D., Skinscapes: Embodiment, Culture, and Environment, v: Classen, C., The Book of Touch, New York 2005, 27-39.

Husserl, E., Cartesian Meditations: An Introduction to Phenomenology, The Hague 1961.

Husserl, E., Ideas Pertaining to a Pure Phenomenological Philosophy II: Studies in the Phenomenology of constitution, Dodrech 1989.

Husserl, E., Kriza Evropskih znanosti i transcedentalna fenomenologija, Zagreb 1990.

Husserl, E., Logične raziskave: Raziskave k fenomenologiji in teoriji spoznanj, Anthropos 23 (1991), 333-344.

Ihde, D., Introduction: Postphenomenological Research, Human Studies 31 (2008), 1-9.

Krpič, T. O telesnih dogodkih, v: Klanjšek, M., in drugi, Raziskovalno delo podiplomskih študentov v Sloveniji - Ena znanost, Ljubljana 2003, 173-184.

Krpič, T., Kognitivno delovanje človeškega telesa, Ljubljana 2004. 
Krpič, T., Your Body, My Pain. Referat predstavljen na BSA Annual Conference 2008: Social Worlds, Natural Worlds, Warwick, $28^{\text {th }}$ $-30^{\text {th }}$ March 2008.

Leder, D., The Absent Body, Chicago 1990.

Leder, D., Flesh and Blood: A Proposed Supplement to Merleau-Ponty, v: Welton, D., The Body: Classic and Contemporary Readings, Oxford 1999, 200-210.

Mauss, M., Techniques of Body, Economy and Society 2 (1973), 70 88.

Merleau-Ponty, M., Phenomenology of Perception, London 1945/1962.

Merleau-Ponty, M., Basic Writings, London 2004.

Miller, G. A., The Magical Number Seven, Plus or Minus Two: Some Limits on Our Capacity for Processing Information, Psychological Review 63 (1956), 81-97.

Nagataki, S., Hirose, S., Phenomenology and the Third Generation of Cognitive Science: Towards a Cognitive Phenomenology of the Body, Human Studies 30 (2007), 219-232.

Reynaert, P., Intersubjectivity and Naturalism - Husserl's Fifth Cartesian Meditation Revisited, Husserl Studies 17 (2001), 207-216.

Schutz, A., Collected Papers I: The Problem of Social Reality, London 1962.

Schutz, A., Collected Papers II: Studies in Social Theory, London 1964.

Schutz, A., Collected Papers III: Studies in Phenomenological Philosophy, London 1975. 
Shilling, C., The Body and Social Theory, London 1993.

Shilling, C., The Body in Culture, Technology \& Society, London 2005.

Shilling, C., Changing Bodies: Habit, Crisis and Creativity, London 2008.

Steinbock, A. J., Saturated Intentionality, v: Welton, D., The Body: Classic and Contemporary Readings, Oxford 1999, 178-199.

Sullivan, S., Domination and Dialogue in Merleau-Ponty's Phenomenology of Perception, Hypatia 12 (1997), 1-19.

Synnott, A., The Body Social: Symbolism, Self and Society, London 1993.

Turner, B. S., Recent Developments in the Theory of the Body, v: Featherstone in ostali, The Body: Social Process and Cultural Theory, London 1991, 1-35.

Turner, B. S., Regulating Bodies: Essays in Medical Sociology, London 1992.

Turner, B. S., The Body \& Society: Explorations in Social Theory, London 2008 .

Weitman, S., On the Elementary Forms of the Socioerotic Life, Theory, Culture and Society 15 (1998), 71-110. 


\section{POST-PHENOMENOLOGICAL SOCIOLOGY OF THE BODY}

Keywords: body, post-phenomenology, Edmund Husserl, Maurice Merleau-Ponty

\section{Abstract}

This article discusses the works of two classic philosophic writers, Edmund Husserl and Maurice Merleau-Ponty, by focusing on the significance of both writers for the post-phenomenological nature of the sociology of the body. With their reflections on the "living body" and its position in the world, Husserl and Merleau-Ponty both pave the way to phenomenological thought and consolidate its place in the post-phenomenological sociology of the body. 